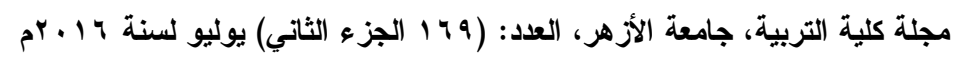

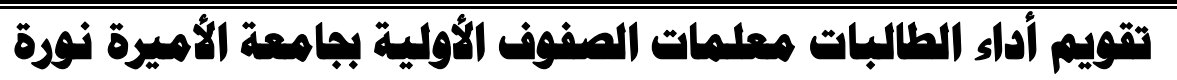 \\ في مقرد استزاتيميات تدربس الاتغة العربية

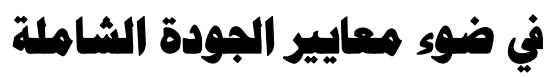

(المطخص:

هدفت الدراسة إلى التعرف على الأداء التدريسي للطالبات معلمات الصفوف

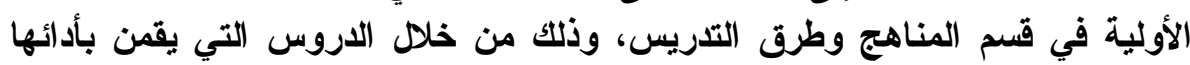

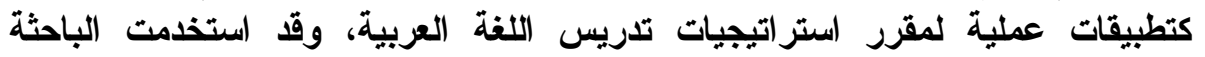

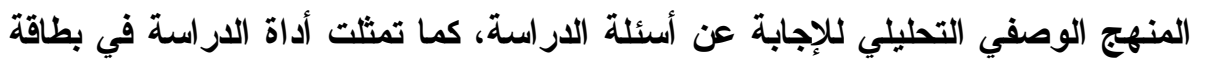

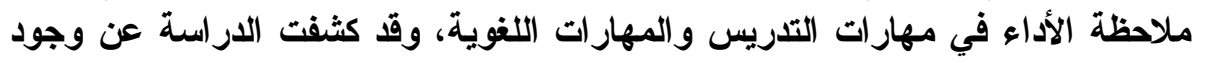

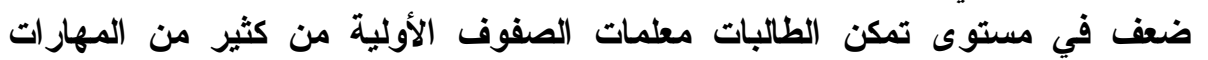

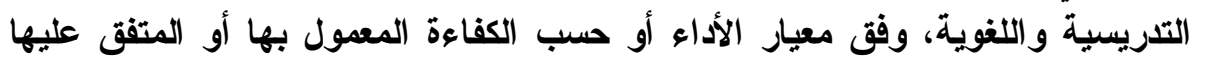

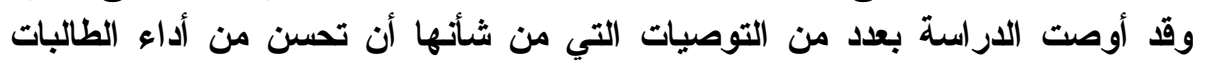

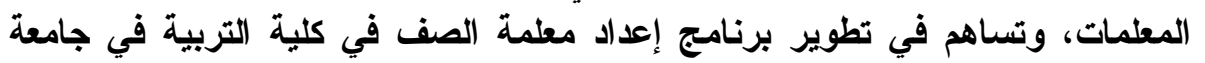
الأميرة نورة.

الكلمات المفتاحية: معلم الصف، المهارات التذريسية، المهارات اللغوية.

المقدمة:

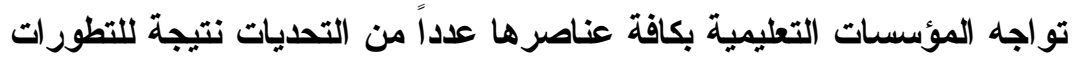

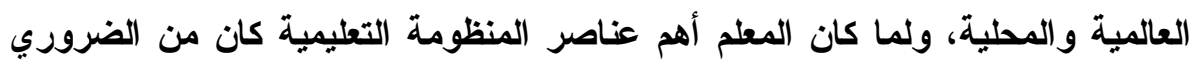

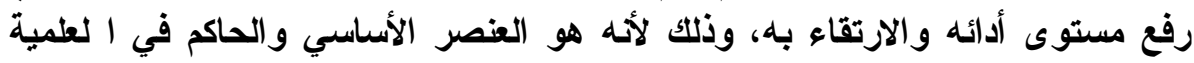

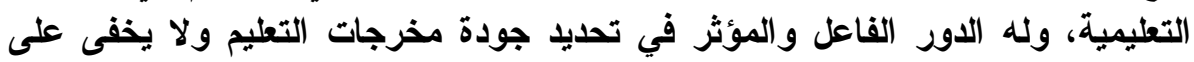

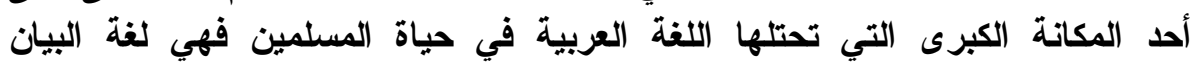

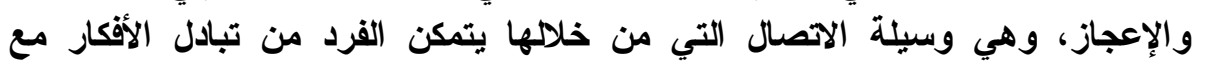

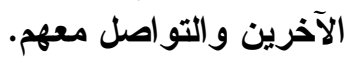

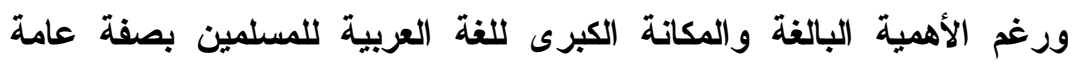

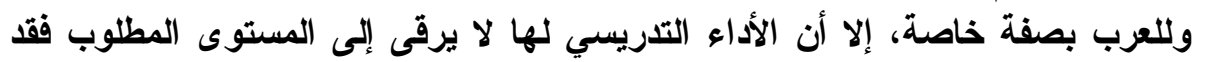

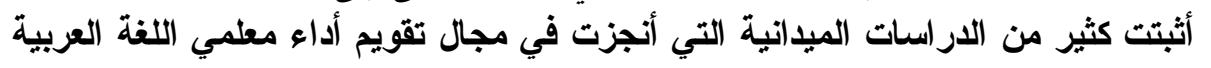

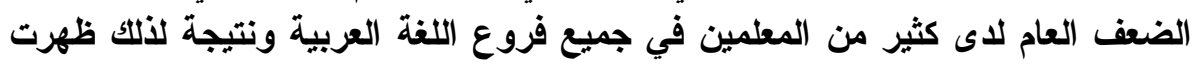

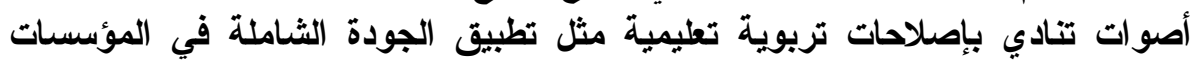

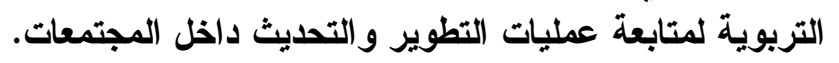




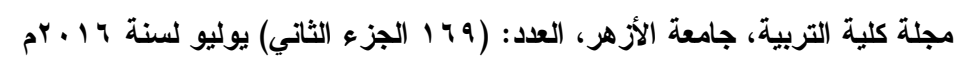

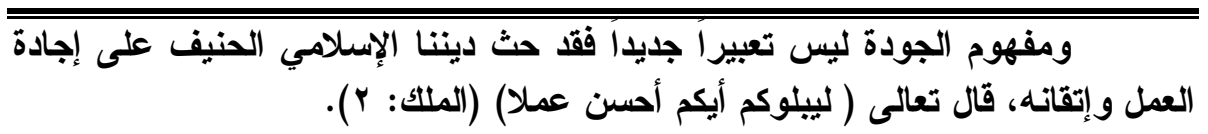

وتعتبر الجودة من أهم الوسائل التي تحسن عملية التعليم وترتقي بمستواه

حيث عملية التعليم ضرورة ملحة تفرضها الحياة المعاصرة.

ويواجه المعلم في جميع التخصصات تحديات كبرى في ظل هذه التهن التغيرات

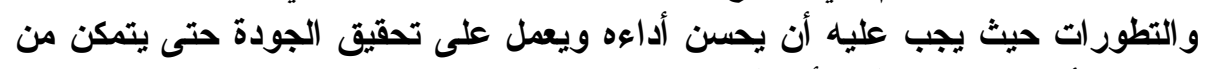

تحقيق الأهداف التعليمية المأمولة (1) أنطو

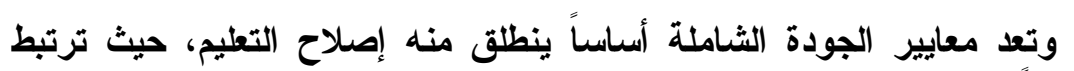

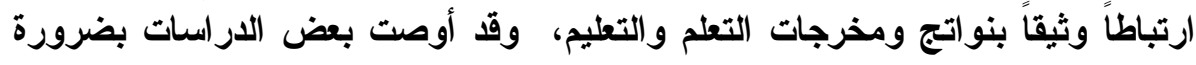

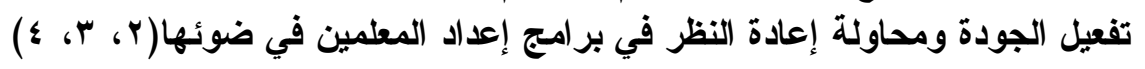

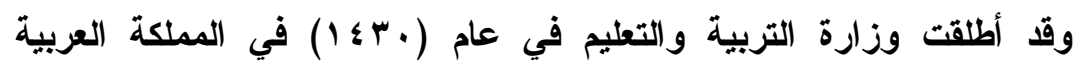

السعودية مشروعا باسم (حسن) وهو برنامج يقوم على تجويد التهائ التعليم في المرحلة

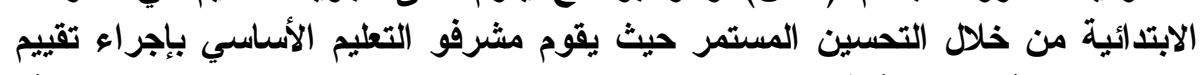

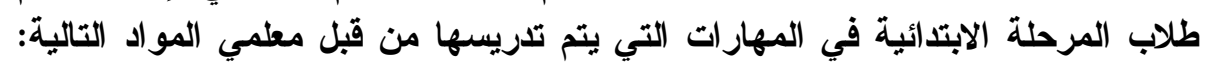

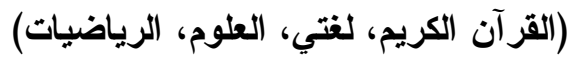

ويستفاد من تحليل النتائج بعد عمليات التقويم في تخطيط البرامج الصعبة

المساندة والإثرائية وتنفيذها، ومن أبرز أهداف هذا بـات المشروع:

• إمداد القائمين على العملية التعليمة بالمعلومات اللازمة لرفع كفاية المعلمين

في توظيف استراتيجيات التدريس لتحسين مستوى التعلم والتعليم.

• اكتشاف مواطن الضعف عند المعلمين في تدريس العلوم والمعارف والمهارات

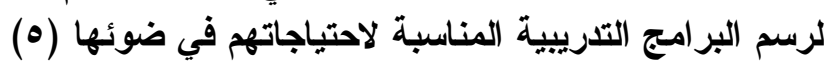

وقد أوصت المؤتمرات والدورات التدريبية والندوات العلمية التي تهتم بمبدأ

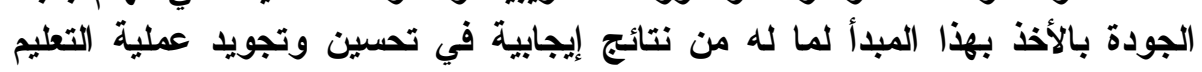

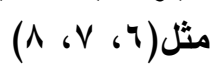

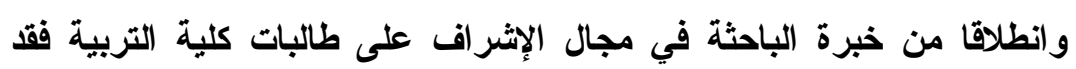

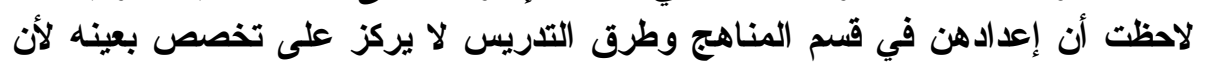

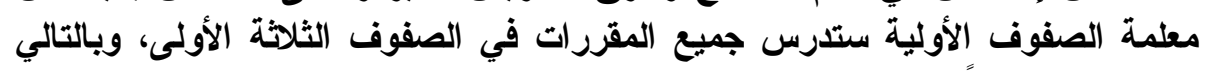

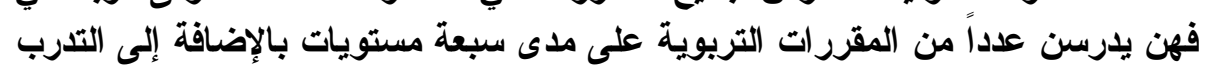

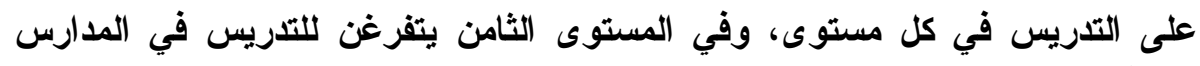
بصفة مستمرة. 
مجلة كلية التربية، جامعة الأزهر ، العدد: (9 17 الجزء الثاني) يوليو لسنة 1 أبrم

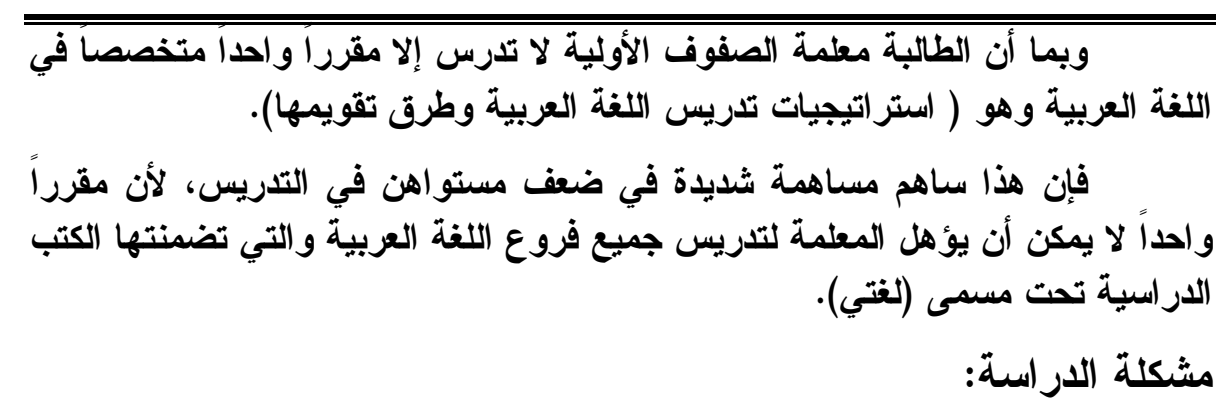

إن إعداد معلمة الصفوف الأولية عملية مهمة تحتاج إلى جهود متكاتفة من كل

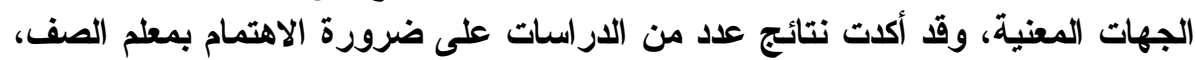

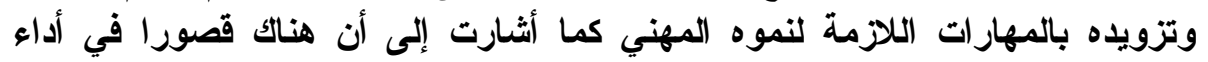

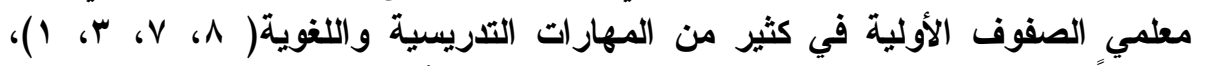

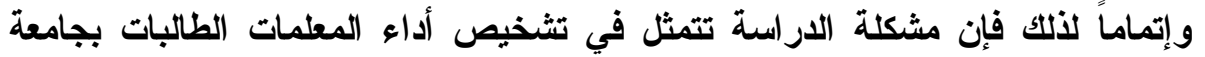

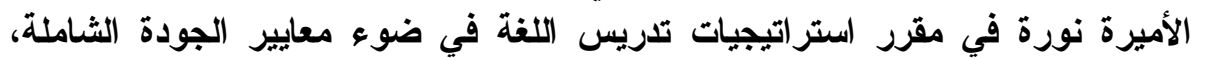

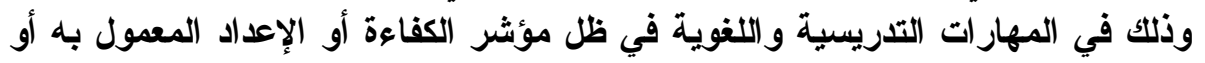

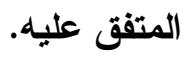

وهذا ما دفع الباحثة لهذه الارسة، وتتحدد مشكلة الدراسة في الأسئلة التالية: • ما مهارات التدريس المتطلبة للطالبات معلمات الصفوف الأولية في ضوء

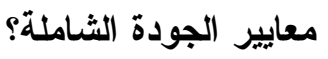

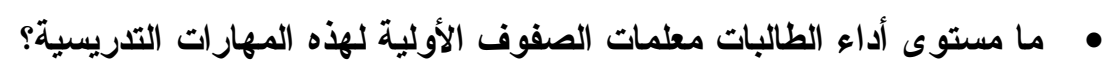
• ما مهارات اللغة المتطلبة للطالبات معلمات الصفوف الأولية في ضوء معايير

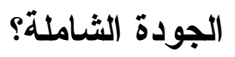

• ما مستوى أداء الطالبات معلمات الصفوف الأولية لهذه المهارات اللغوية؟ • ما مدى تمكن الطالبات معلمات الصفوف الأولية من المهارات التدريسية و اللغوية؟ مان

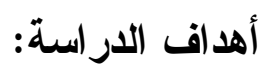

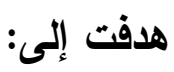

• تحديد المهارات التدريسية والمهارات اللغوية التي تحتاجها الطالبة معلمة الصفوف الأولية في ضوء معايير الجودة الشاملة. 


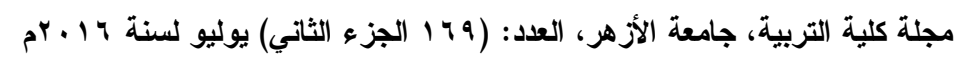
• قياس مدى تمكن الطالبة معلمة الصفوف الأولية من بعض المهارات التدريسية، وبعض المهارات اللغوية.

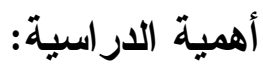

تنطلق أهمية الاراسة من الاعتبارات التالية:

• أهمية المهارات التدريسية واللغوية للطالبات المعلمات باعتبارهما مهمين

لنجاح المعلمة.

• تقدم بطاقة ملاحظة تثنتمل على عدد من المهار ات التدريسية واللغوية.

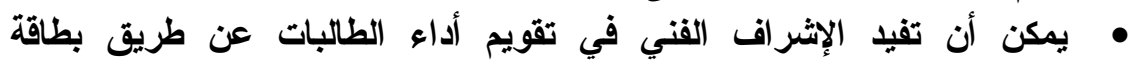

الملاحظة المستخدمة فيها.

• يمكن أن تفيد الطالبات المعلمات في تحديد مستوى إتقاتهم للمهارات التدريسية

و اللغوية وبالتالي العمل على تنميته.

• تهتم بمعايير الجودة الثاملة وتقييم الطالبات معلمات الصفوف الأولية في

ضوئها.

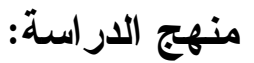

سارت الباحثة على المنهج الوصفي التحليلي حيث يعد أنسب المناهج لهذه

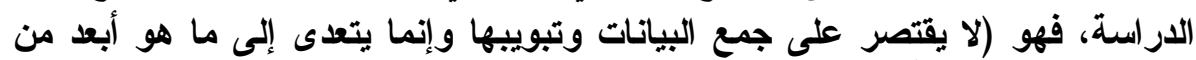

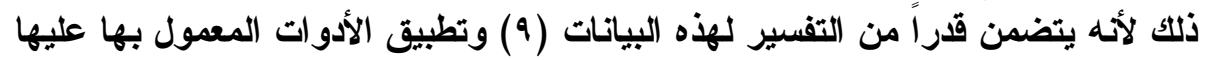

بعد ضبطها.

حدود الار اسة:

اقتصرت الدر اسة على الحدود التالية:

1. بعض مهارات التدريس العامة، وبعض العالة مهاردات اللغة التي يجب أن تثقتها

الطالبة معلمة الصفوف الأولية.

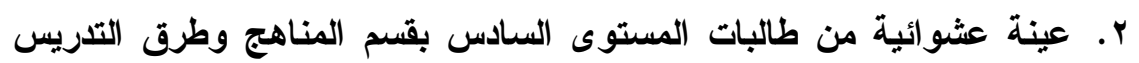
مسار معلمة الصفوف الأولية حيث أن مقرر (استراتيجيات تدريس اللغة

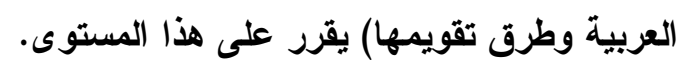

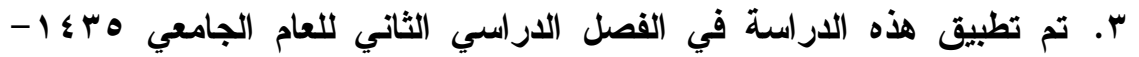

4.

ع. تم تنفيذ الدروس من قبل الطالبات المتدربات أثناء دراسة المقرر.

ه. جميع الاروس التي تدربت عليها الطالبات من كتب (لغتي) للصفوف الثات الثلاثة

الأولى. 
مجلة كلية التربية، جامعة الأزهر، العدد: (9 17 الجزء الثاني) يوليو لسنة 17 ـ بام ج. المهارات التي تمت ملاحظتها من قبل الباحثة هي تلك المهارات التي حددت جلته مسبقاً في بطاقة الملاحظة.

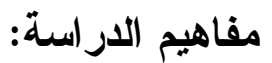

التقويم: في اللغة مأخوذ من تقويم الثيء إذا تبينت قيمته وتعدل واستوي (11)

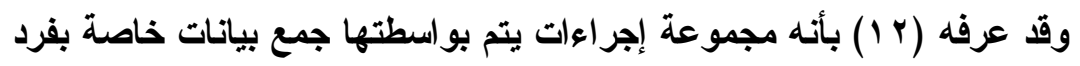

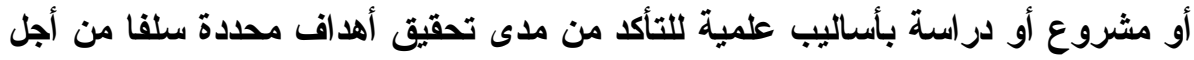
اتخاذ قرارات معينة. ويعرف تقويم الأداء بأنه: عملية جميع بيانات ومعلومات، ومحاولة وضعها في شكل معين وذلك بهاف اتخاذ قرار

معين (T) وتعرف الباحثة تقويم الأداء إجر ائياً بأنه: إصدار الأحكام على أداء الطالبات معلمات الصفوف الأولية أثناء تلدريسهن لمقررات (لغتي) خلال فترة تدريبهن على مهارات التّريس في الجانب العملي لمقرر (استر اتيجيات تدريس اللغة العربية وطرق تلفرية تلفيمها). وذلك بهذف تعزيز الأداء المتقن، و العمل على علاج القصور في الأداء غير

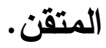

الطالب المعلم: هو الطالب الذي تعده كلية التربية ليكون معلماً فيما بعد (؛ 1) وتعرف الباحثة الطالبة المعلمة إجرائياً: بأتها الطالبة المنتظمة في قسم المناهج وطرق التدريس (مسار معلمة الصفوف الأولية) والمسجلة في مقرر (استراتيجيات تدريس اللغة العربية وطرق تقويمها). معاييز الجودة الشاملة: يعرفها (10) بأنها مجموعة من المعايير التعليمية

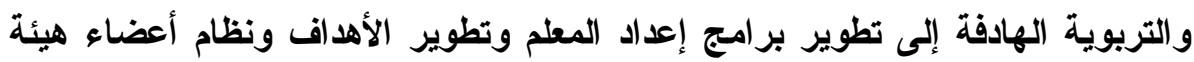
التدريس ورفع مستوى جودة التعليم ومخرجاته وتطويره وتحسينه. وتعرفها الباحثة إجرائياً بأنها: مجموعة من الضوابط الخاصة بالمهارات التدريسية و اللغوية والتي تهدف إلى تحسين وتجويد أداء الطالبة معلمة الصفوف الأولية بكلية التربية بجامعة الأميرة نورة. 
الإطار النظري و الدراسات السابقة: (أداء المعلم وتقويمه) تقويم أداء الطالب المعلم:

يمثل المعلم المحور الأساسي في النظام التربوي حيث يقع على عاتقه العبء الأكبر في تحقيق الأهداف التربوية.

ويحد ( بالمالمتطلبات المهنية المعاصرة الخاصة بالجوانب الأكاديمية و التربوية والثقافية للمعلم في ضوء الجودة الثناملة في:

1. امتلاك المعرفة بصفة عامة، وامتلاك قاعدة عميقة من المعرفة في مجال التخصص. - (متلاك r. الاهتمام بالدراسات التي تربط بين أكثر من تخصص في آن واحد.

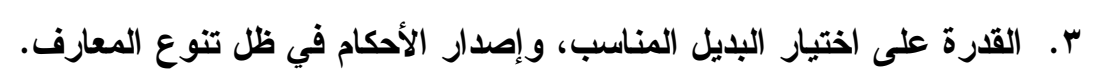

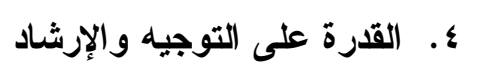
0. الإمام بقار مناسب من الثقافة المعلوماتية وتقنية المطومات. T. استخدام مهارات الحاسب في التطليم والتواصل مع الطلاب.

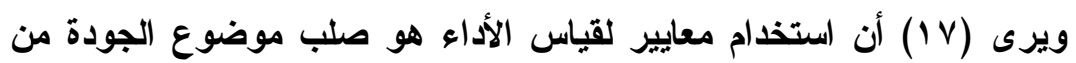
خلال وضع مؤشرات لتلك الجودة في عناصر العملية التعليمية مثل التنمية المهينة للمعلم. ومن الار اسات التي اهتمت بهيذا المحور:

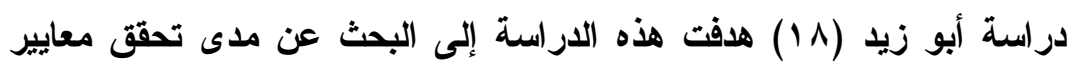

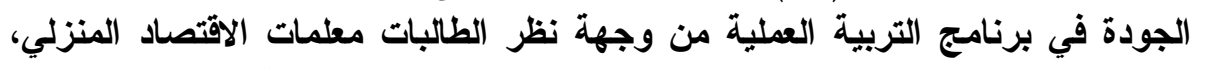

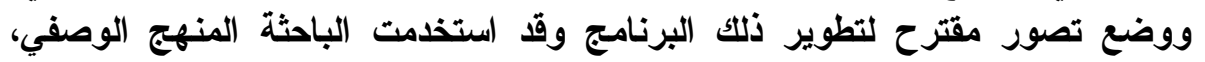

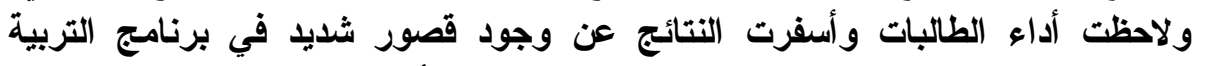

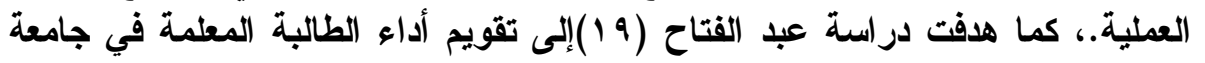

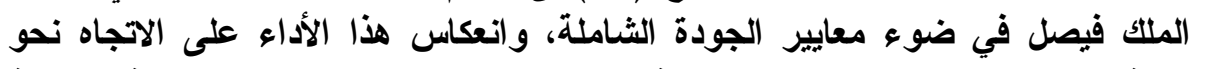

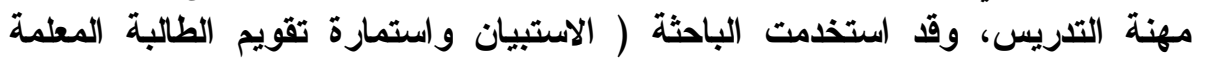

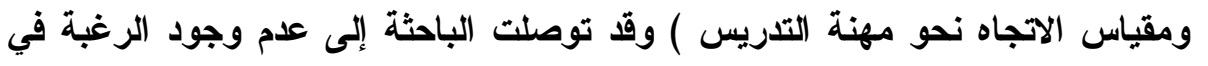




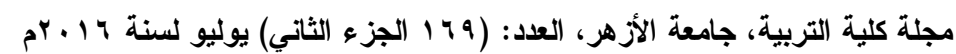

التدريس عند الطالبات المعلمات، والقصور في أدائهن في غالبية محاور البطاقة.

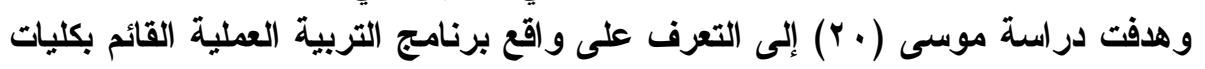

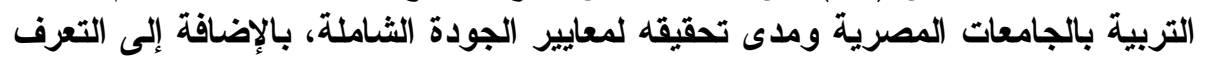

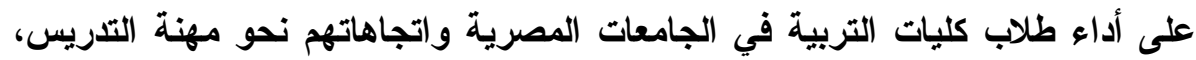

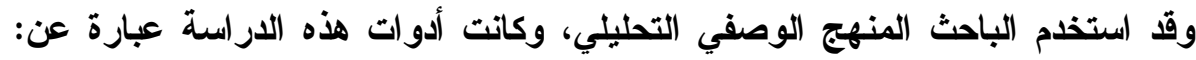

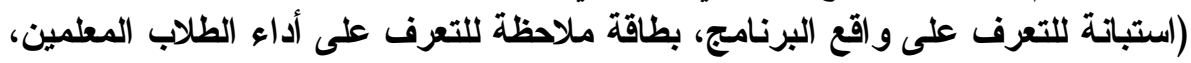

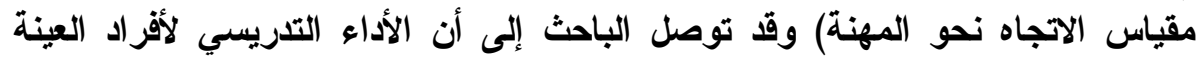

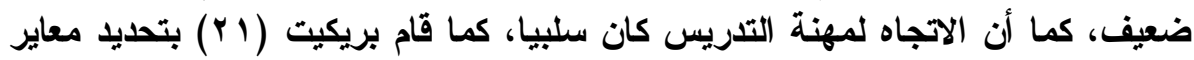

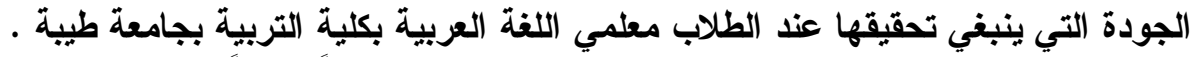

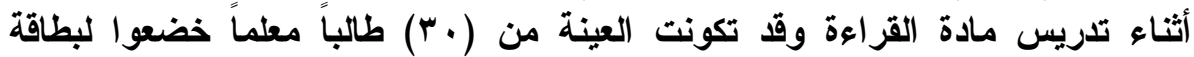

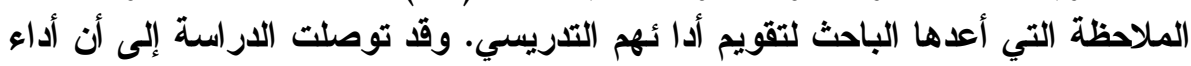
الطلاب المعلمين كان ضعيفا إلى حد ما في جميع المحاور.

\section{معلم الصف:}

لا يخفى على أحد أهمية مرحلة التعليم الأساسي، حيث أنه يهدف إلى إعداد

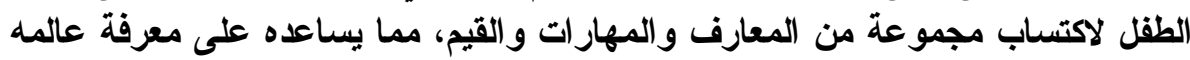

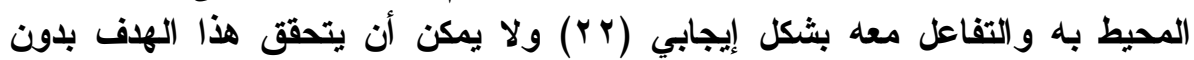

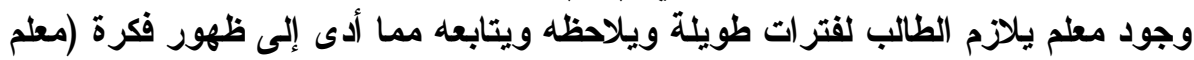

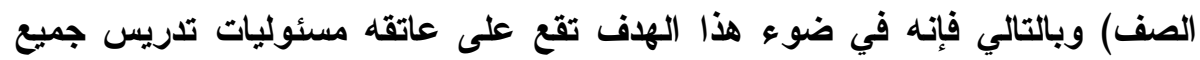

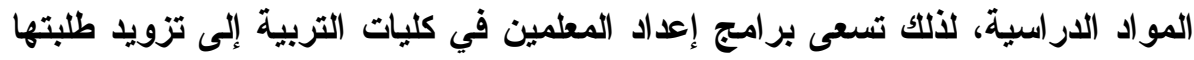

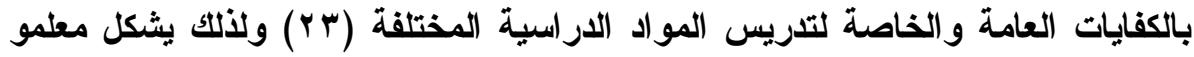

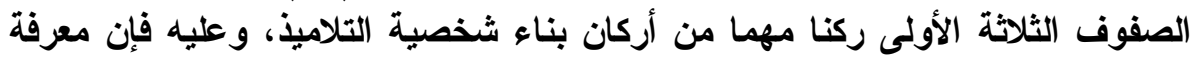

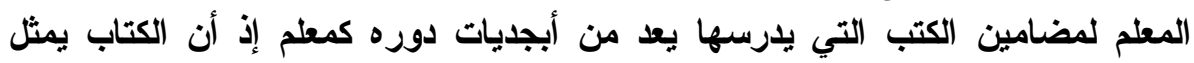

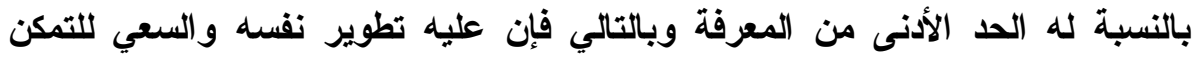

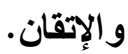

\section{ومن الار اسات التي اهتمث بهذا المحور :}

دراسة أبو لطيفة (؟ Y) وقد هدفت إلى التعرف على درجة اكتساب طلبة معلم

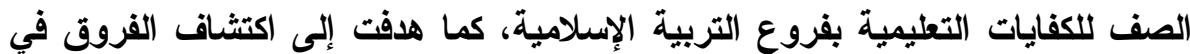

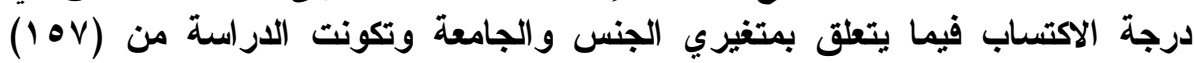

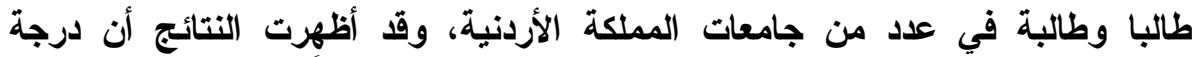
اكتساب الطلبة للكفايات مرتفعة كما أظهرت عدم وجود فروق تبعاً للمتغيرين. 


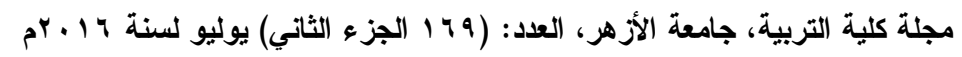

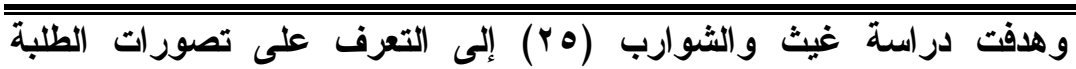

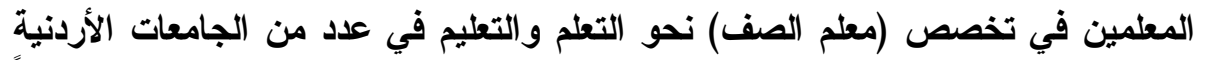

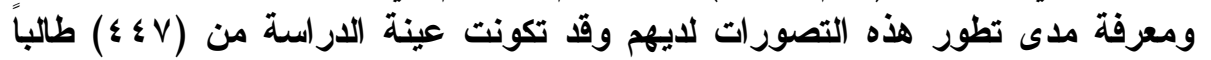

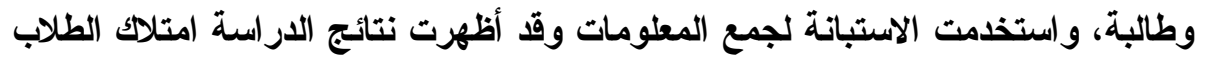

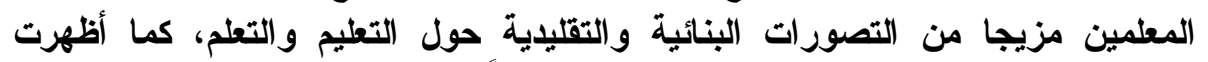

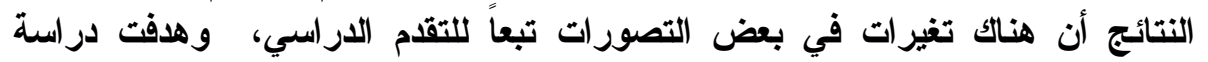

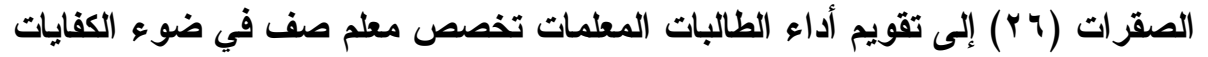

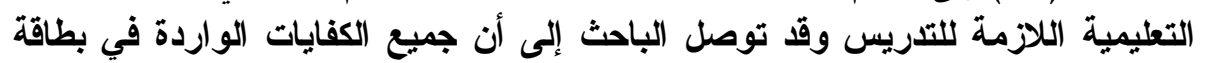
الملاحظة قد حصلت على تقديرات مرتفعة. الجودة الشاملة وعملية التعليم:

لقد شهر العالم في السنوات الأخيرة تطورات سريعة ومتلاحقة في مختلف

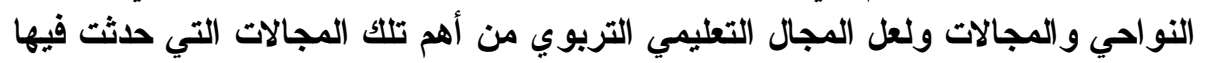

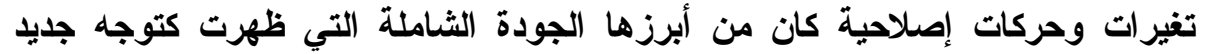
سعت كافة المؤسسات التعليمية إلى الأخذ بهان آبرات

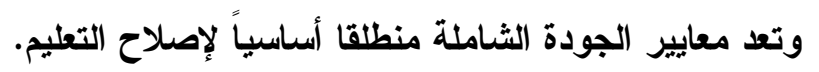

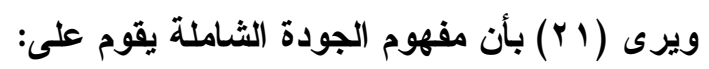

• إيجاد بيئة تعليمية فعالة بين مكونات المنظومة التعليمية.

• إيجاد فرص تعاونية مثمرة وبناعة في البيئة التعليمية. • • • • •

وقد اشتقت الباحثة معايير ومؤشرات الجودة الشاملة في الأداء التذريسي من المصادر التالية:

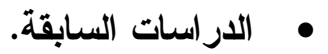 \\ • بعض المؤلفات النظرية. \\ • المستويات المعيارية لوزارة التعليم العالي. \\ واقتصرت الباحثة في الدراسة الحالية على: \\ • المعيار الأول: أخلاقيات المهنة. \\ • المعيار الثاني: إدارة الفصل.
}




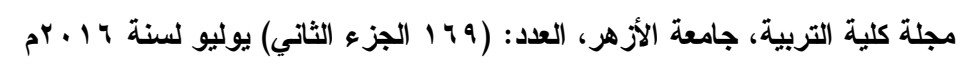

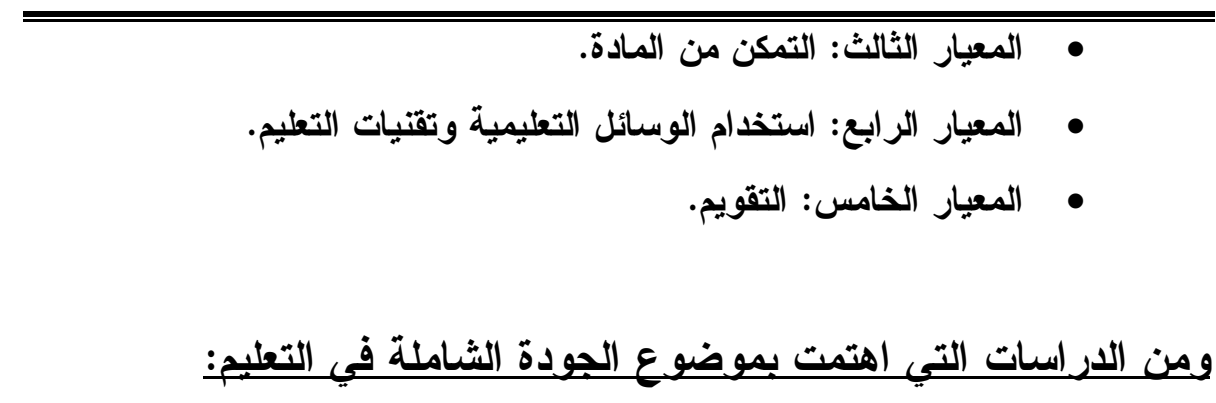

دراسة العايد (rV) هدفت هذه الداراسة إلى تقويم الأداء التدريسي لمعلمي

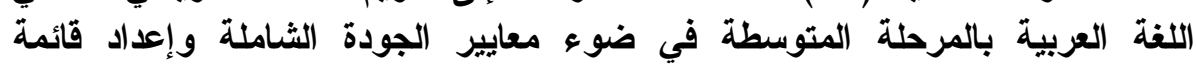
بالمعايير اللازم توافرها في المعلمين والكثف عن نواحي القوة الضعف في أداء اتهم التدريسية.

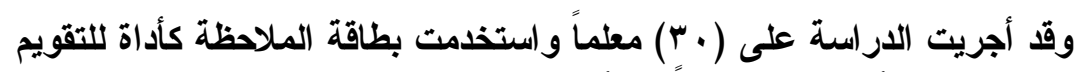
وقد توصل الباحث إلى أن هناك قصوراً في أداء المعلمين في كثير من الجوانب.

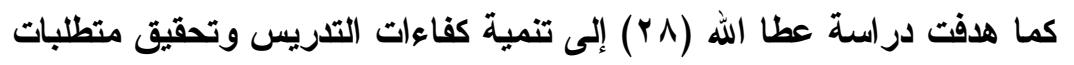

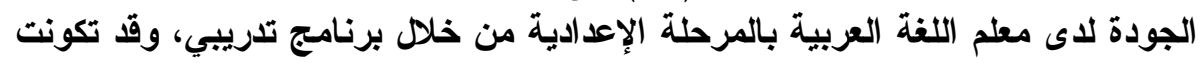

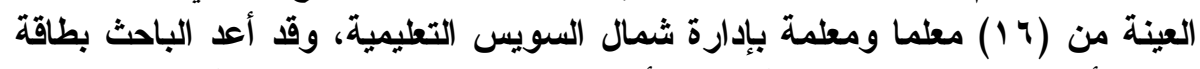

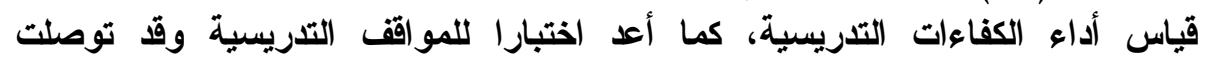
الاراسة إلى فاعلية البرنامج التدريبي.

وهدفت دراسة الروقي (9 ب)، إلى التعرف على مستوى تمكن الطلاب المعلمين

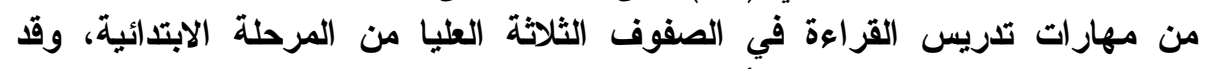

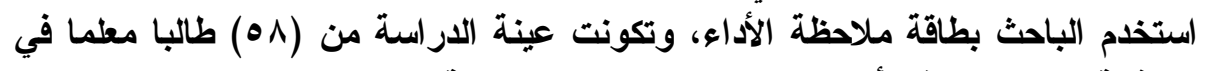

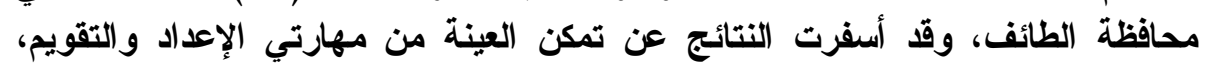
بينما انخفضت درجات الطلاب في مهارة التنفيذ.

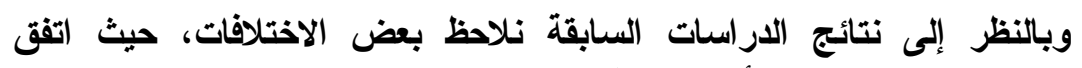

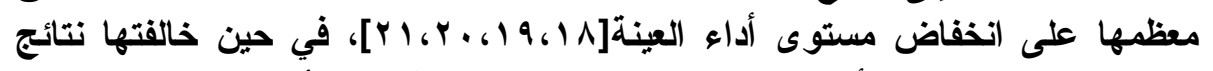

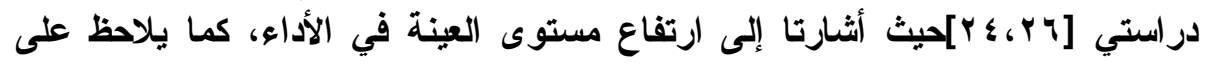

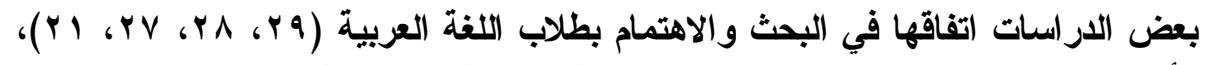

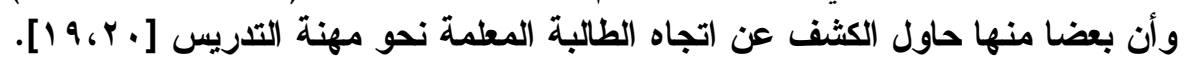
عنية البحث: 
مجلة كلية التربية، جامعة الأزهر ، العدا: (19 19 الجزء الثاني) يوليو لسنة 17 بام

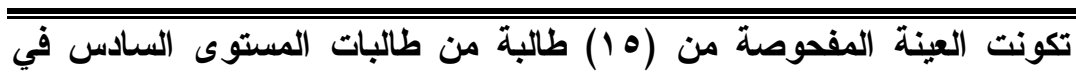

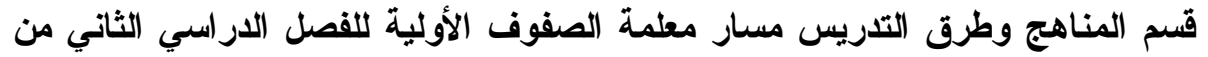

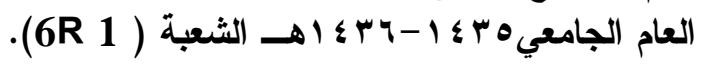

أداة البحث: (إعداد (الباحثة)

تمثلت أداة البحث في بطاقة ملاحظة من إعداد الباحثة وتضم عدداً من مهارات

التدريس و مهارات اللغة.

خطوات إعداد بطاقة الملاحظة:

أولاً: تحديد المهارات وذلك بعد مراجعة الدراسات السابقة والأبب التربوي.

ثانياً: وضع بطاقة الملاحظة في صورتها المبدئية، وقد ضمت ( 0؛ ) مهارة، أمام كل

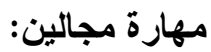
أ ) مستوى الأهمية

ب) المجال المناسب للمهارة

ثالثاً: وضع بطاقة الملاحظة في صورتها النهائية:

قامت الباحثة في هذه المرحلة بخطوتين مهمتين:

1. قياس صدق البطاقة:

قامت الباحثة بعرض البطاقة على عدد من المتخصصين، ومن ذوي الخبرة وبعد قيامهم - مشكورين - بالتحكيم قامت الباحثة بالتعديل على البطاقة في ضونه

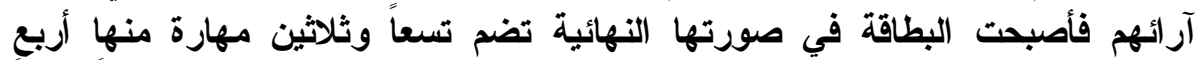
عشرة مهارة لغوية، وخمس وعشرون مهارة تدريسية، وقد وضعت الباحثة سلماً رقمياً

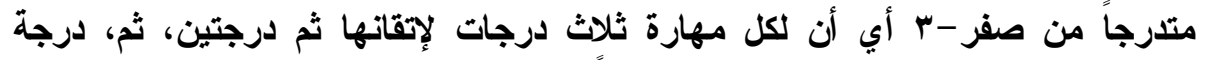
واحدة، ثم صفر في حال عدم القيام بها أصلاً

r . ثبات بطاقة الملاحظة:

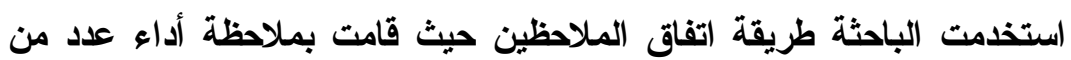

الطالبات معلمات الصفوف الأولية مع إحلى المعلمات المتعاونات بعد أن شرحت لهات لهات لهات

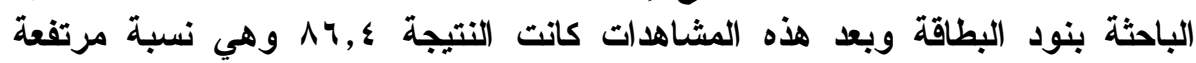
ومطمئنة. 
لقد تم اختيار عينة البحث من طالبات المستوى السادس في قسم المناهج

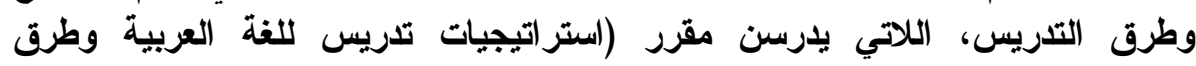

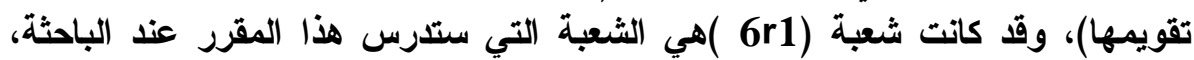

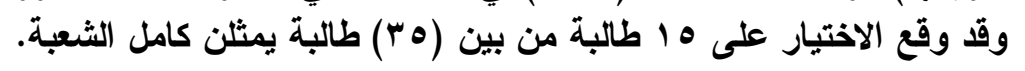

وقد كانت جميع التطبيقات خلا ساعات المقرر البالغة (r) ساعات أسبوعيا

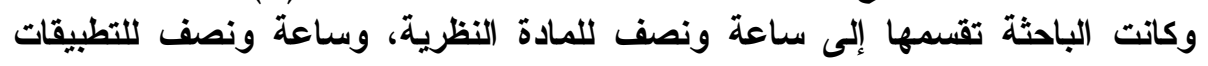

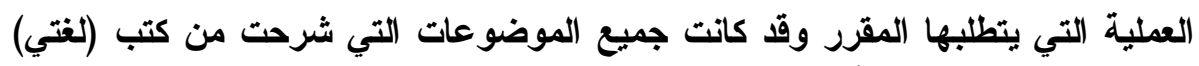
المقررة على الصفوف الأول، الثاني، الثالث، الابتدائي.

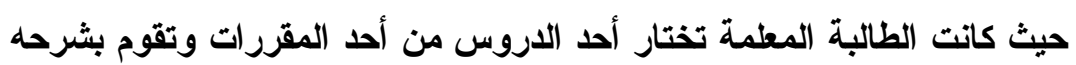

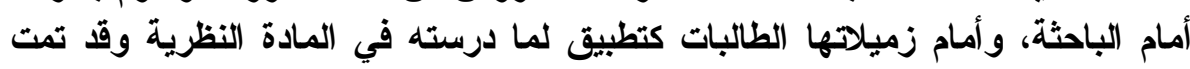

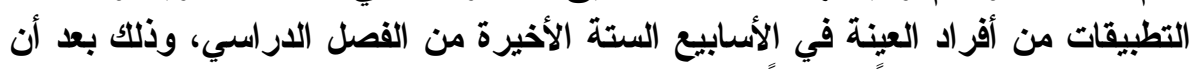

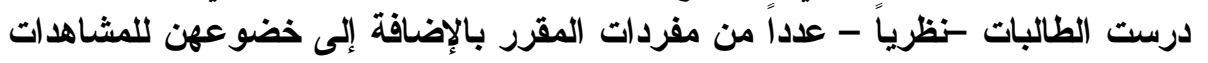
الميانية طوال دراستهن في المستويات السابقة.

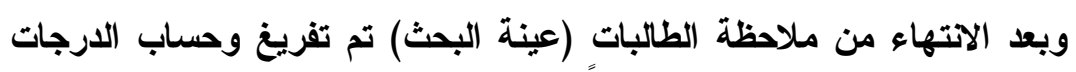

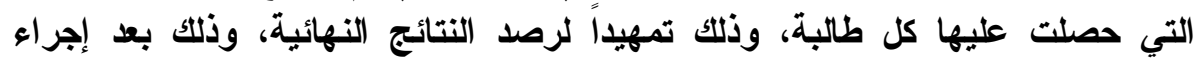
العمليات الإحصائية المناسبة مثل كلية ولئ

$$
\begin{aligned}
& \text { 1. المتوسط الحسابي } \\
& \text { r. النسبة المئوية } \\
& \text { r. الاحصر اف المعياري }
\end{aligned}
$$

نتائج الار اسة ومناقشتها:

نتائج السؤ ال الأول:

للإجابة على السؤال الأول الأي نص على: ما مهارات التدريس المتطلبة للطالبات

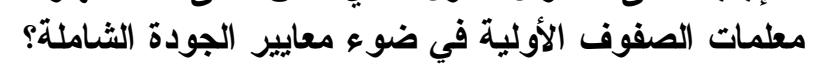

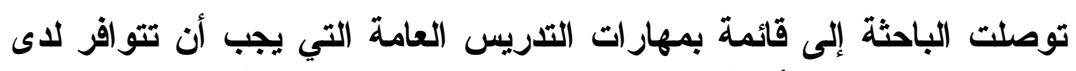

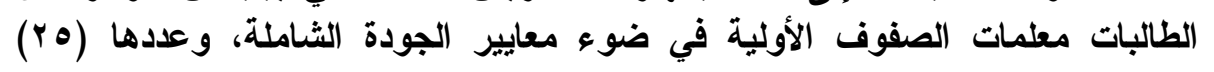
مهارة. نتائج السؤال الثاني: 


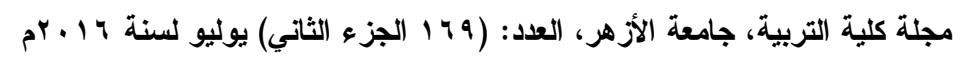

للإجابة على السؤال الثاني الأي نص على: ما مستوى أداء الطالبات معلمات الصفوف

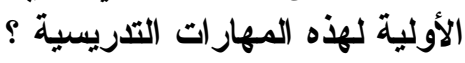

التم إيجاد المتوسط الحسابي الاحمر اف المعياري لارجات الطالبات في مهارات التدريس العامة كما في الجدول التالي:

جدول رقم (1) (1) (1)

\begin{tabular}{|c|c|c|}
\hline الاتحر اف المعياري & المتوسط الحسابي & عدد الطالبات \\
\hline $7, .8$ & $\varepsilon,, q$. & 10 \\
\hline
\end{tabular}

كما تم إيجاد النسب المئوية للطالبات في مهارات التّريس العامة كما في

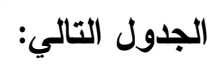

جدول رقم (r) (ب)

النسب المئوية للطالبات في المهارات التدريسية العامة.

\begin{tabular}{|c|c|}
\hline النسبة المئوية & رقم الطالبة \\
\hline $0 \leq, 79$ & 1 \\
\hline Or, rr & $r$ \\
\hline$\varepsilon q, r r$ & $r$ \\
\hline$\leq 7,74$ & $\varepsilon$ \\
\hline or,... & 0 \\
\hline$\Delta V, r r$ & 9 \\
\hline $0 \leqslant, 74$ & $v$ \\
\hline $0 \wedge, 74$ & $\Lambda$ \\
\hline$\leq 7,74$ & 9 \\
\hline or,.. & 1. \\
\hline$\leq 7,79$ & 11 \\
\hline $7 \varepsilon, \cdots$ & Ir \\
\hline rq, , & ir \\
\hline$r q, \ldots$ & $1 \varepsilon$ \\
\hline
\end{tabular}

$-14 .-$ 
مجلة كلية التربية، جامعة الأزهر ، العدد: (19 19 الجزء الثاني) يوليو لسنة 17 .بץم

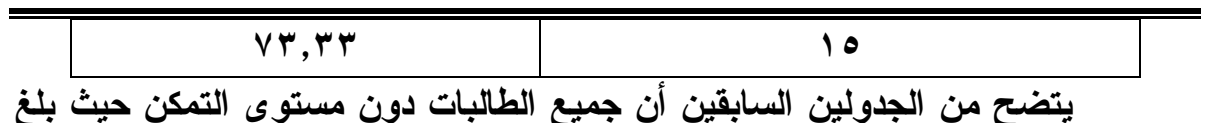

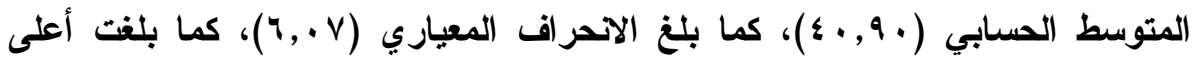

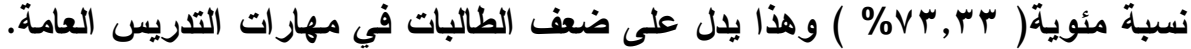

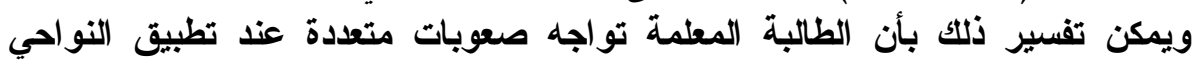

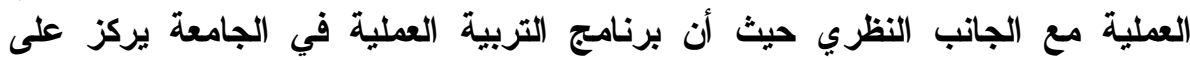

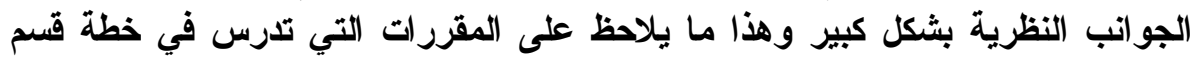

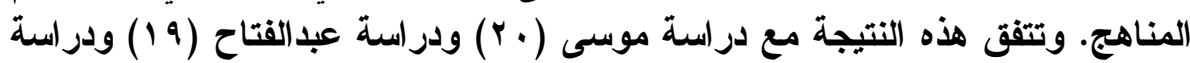

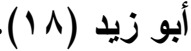

نتائج السؤ ال الثالث:

للإجابة على السؤال الثالث الذي نص على: ما مهارات اللفة المتطلبة للطالبات

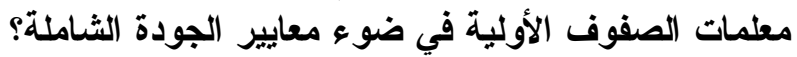

توصلت الباحثة إلى قائمة بالمهارات اللغوية التي يجب أن تتوافر لاى الطالبات

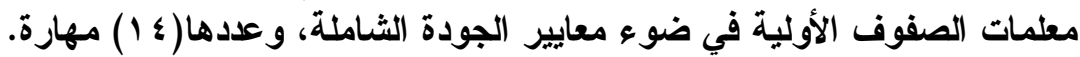

نتائج السؤ ال الر ابع:

للإجابة على السؤال الرابع الأي نص على: ما مستوى أداء الطالبات معلمات الصفوف الأولية لهذه المهارات اللغوية؟ تم حساب المتوسط الحسابي والاتحر افت المعياري لارجات الطالبات في المهارات التدريسية الخاصة باللغة العربية

جدول رقم (r)

\begin{tabular}{|c|c|c|}
\hline الاتحر اف المعياري & المتوسط الحسابي & عدد الطالبات \\
\hline$\varepsilon, V_{0}$ & $Y Y, Y \varepsilon$ & 10 \\
\hline
\end{tabular}

كما تم حساب النسب المئوية لارجات الطالبات في مهارات اللغة :

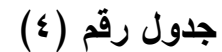

\begin{tabular}{|c|c|}
\hline النسبة المئوية & رقم الطالبة \\
\hline $0 \leq, V$. & 1 \\
\hline$\Delta r, r \wedge$ & $r$ \\
\hline $0, \ldots$ & $r$ \\
\hline rr,rr & $\varepsilon$ \\
\hline $0, \ldots$ & 0 \\
\hline$\varepsilon V, 71$ & 7 \\
\hline
\end{tabular}

$-|r|-$ 
مجلة كلية التربية، جامعة الأزهر ، العدد: (19 19 الجزء الثاني) يوليو لسنة 17 .بץم

\begin{tabular}{|c|c|}
\hline$T \leqslant, Y$. & $\mathrm{V}$ \\
\hline $7 V, T 1$ & $\Lambda$ \\
\hline$\varepsilon \theta, r r$ & 9 \\
\hline $0, \ldots$ & 1. \\
\hline$\varepsilon \theta, r r$ & 11 \\
\hline $0 V, 1 \leq$ & Ir \\
\hline$r \cdot, 90$ & $1 \%$ \\
\hline Or, & $1 \varepsilon$ \\
\hline$\vee \wedge, \diamond \vee$ & 10 \\
\hline
\end{tabular}

يتضح من الجدولين السابقين أن الطالبات دون مستوى التمكن. حيث بلغ إهي

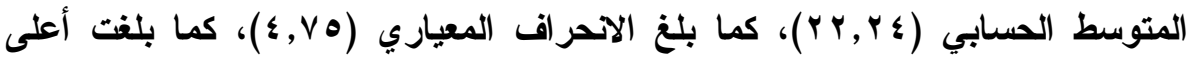

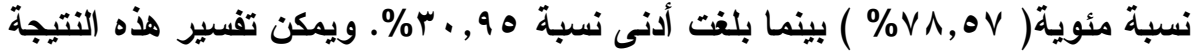

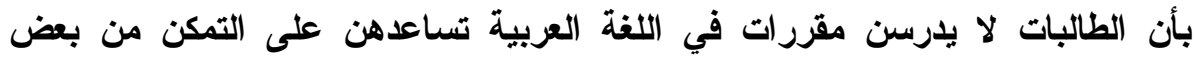

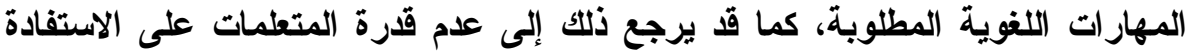

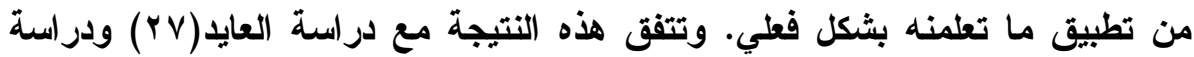

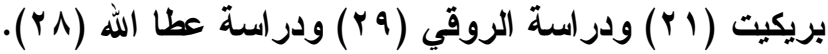
نتائجج السؤ ال الخامس:

للإجابة على السؤال الخامس الذي نص على: ما مدى تمكن الطالبات معلمات الصفوف الأولية من المهارات التدريسية وال اللغوية؛

تم إيجاد المتوسط الحسابي الاتحر اف المعياري لارجات الطالبات الكلية كما في

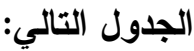

جدول رقم ( ال)

\begin{tabular}{|c|c|c|}
\hline الاتحر اف المعياري & المتوسط الحسابي & عدد الطالبات \\
\hline $1 \ldots r$ & $7 \leqslant .10$ & 10 \\
\hline
\end{tabular}

يتضح من الجدول السابق أن مستوى أداء الطالبات للمهارات التدريسية والمهارات اللغوية بصفة عامة دون المستوى المطلوب، حيث بلغ المتوسط الحسابي

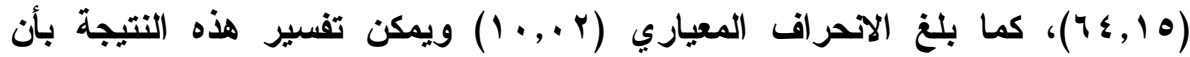

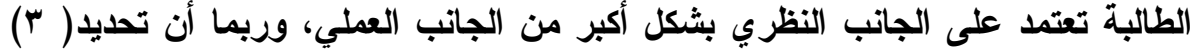

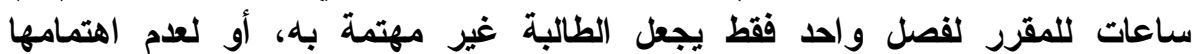


مجلة كلية التربية، جامعة الأزهر، العدد: (9 19 الجزء الثاني) يوليو لسنة 17 بام

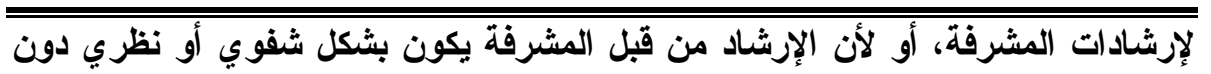
مساعدة الطالبة المعلمة في الناحية التطبيقية أو العملية.

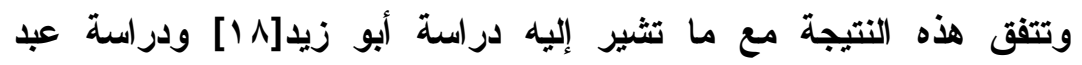

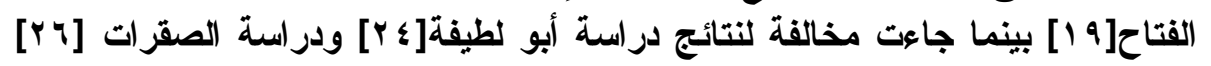
التي أثشارت إلى ارتفاع في مستوى المعلمين في الكفايات التدريسية.

توصيات الار اسة:

العناية بمقرر (استراتيجيات تدريس اللغة العربية ) وإعادة النظر فيه بحيث

يحتوي على تلريبات عملية للطالبة المعلمة.

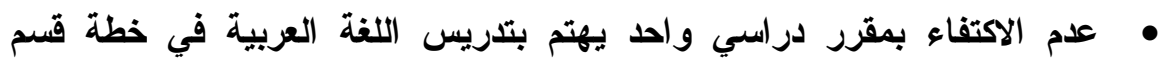

المناهج وطرق التدريس في كلية التربية جامعة الأميرة نورة.

الربط بين الإعداد النظري والإعداد التطبيقي العملي للطالبة المعلمة.

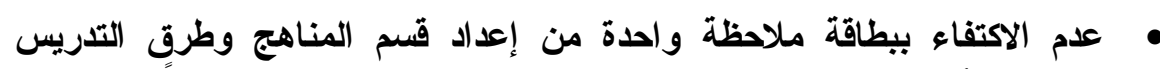

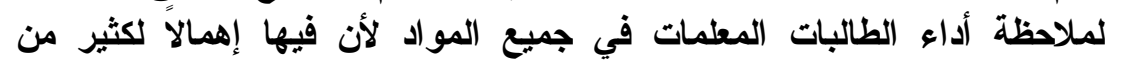

المهارات الخاصة باللغة العربية.

• بناء بطاقة ملاحظة خاصة بمادة (لغتي) للصفوف الأولية.

إدراج موضوع الجودة الثاملة في برامج إعداد معلمة الصفوف الأولية.

تقديم برامج إثرائية للقائمات على تدريب الطالبات معلمات الصفوف الأولية.

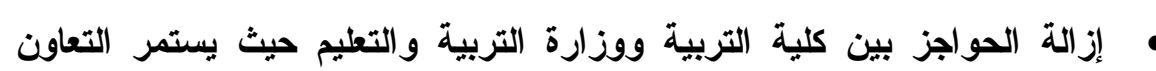

وتبادل الخبرات بينهما والإفادة من إمكانات كل منهما.

المقترحات:

تقترح الباحثة إجر اء الدراسات التالية:

- Irr 
مجلة كلية التربية، جامعة الأزهر، العدد: (9 17 الجزء الثاني) يوليو لسنة 17 ـ بام • دراسة تهاف إلى تقويم مقرر ( استراتيجيات تلاريس اللغة العربية) بقسم

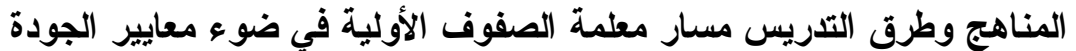

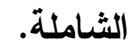

• دراسة تهاف إلى بناء برنامج لتطوير أداء الطالبات معلمات الصفوف الأولية

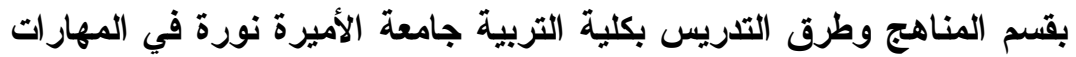

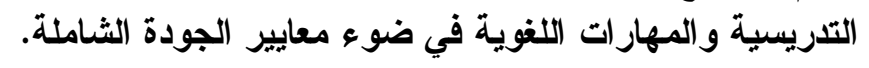

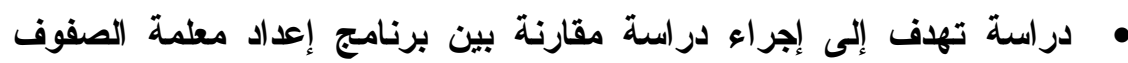

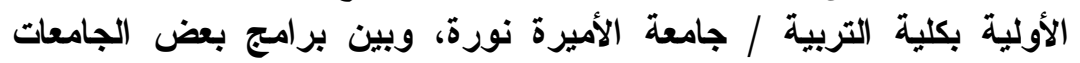

\section{المر اجع:}

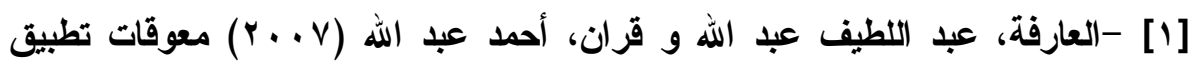

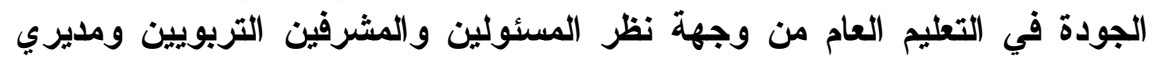

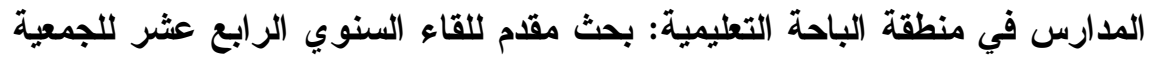

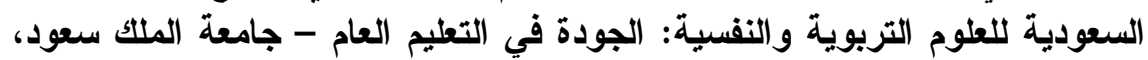

$$
\text { القصيم. }
$$

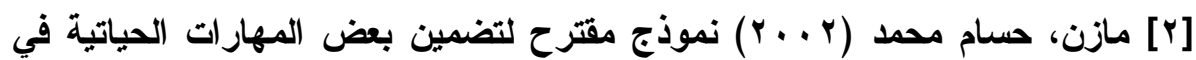

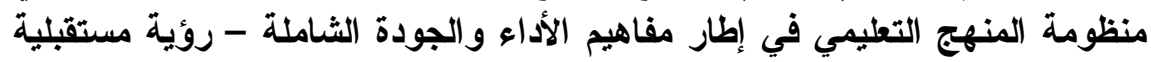

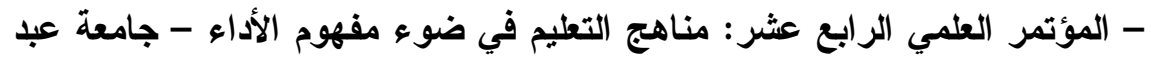

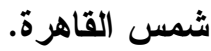

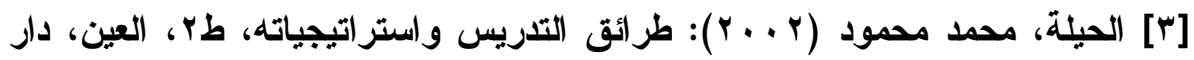

$$
\text { الكتاب الجامعي. }
$$

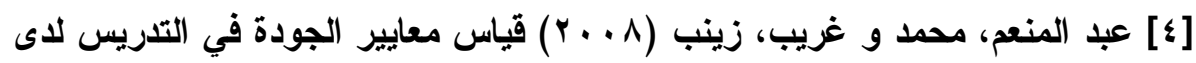

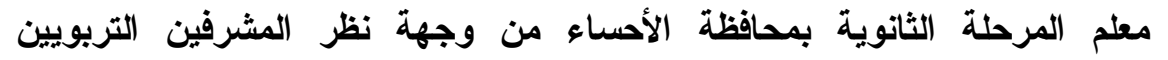
ومقترحاتهم للتنمية المهنية مجلة القراعة وائة والمعرفة.

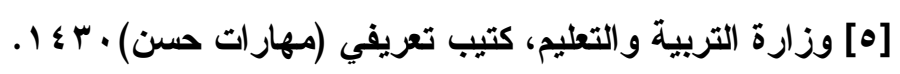


مجلة كلية التربية، جامعة الأزهر، العدد: (9 17 الجزء الثاني) يوليو لسنة 17 ـ بام

[†][المؤتمر العلمي الثالث بعنوان: تكوين المعلم في ضوء معاييز الجودة الثاملة بكليات

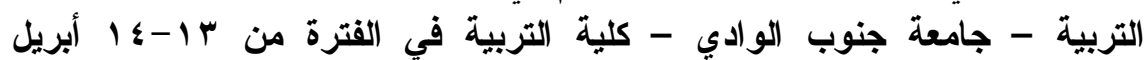

$$
\cdot(r, 0)
$$

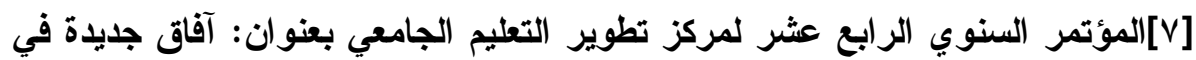

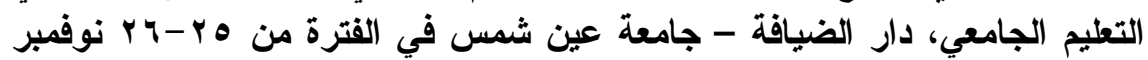

$$
\text { (r..v) }
$$

[^] المؤتمر العلمي الرابع - الدولي الأول بعنوان: جودة كليات التربية والإصلاح

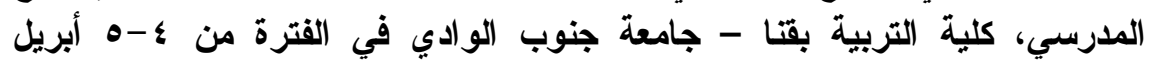

[9] عبد الحميد، جابر و كاظم، أحمد مناهج البحث في التربية وعلم النفس - القاهرة،

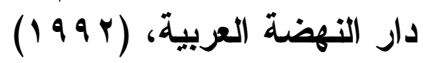

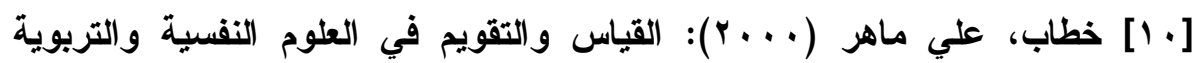
والاجتماعية، القاهرة، مكتبة الأنجلو المصرية.

[11] مجمع اللغة العربية(د ت ) المعجم الوسبط، دار الفكر، القاهرة.

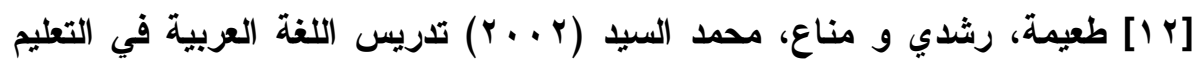

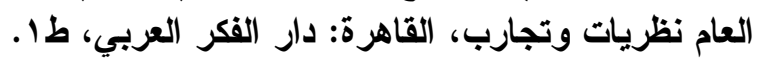

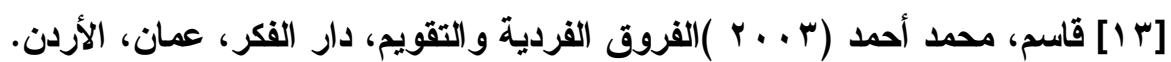

[؛ 1 ] بادي، غسان خالد تعديد حاجات الأداء التعليمي للطالب المعلم في التربية

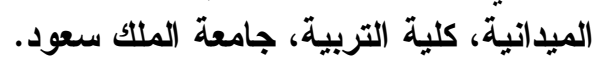

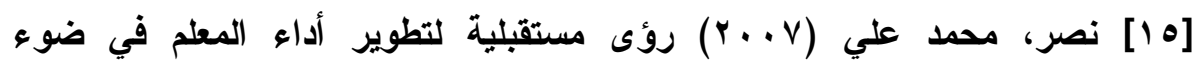

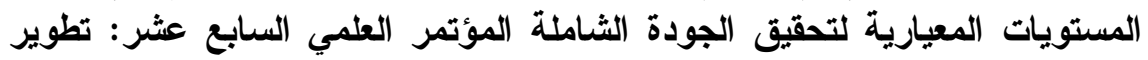
مناهج التعليم في ضوء معايير الجودة، المجلد الأول.

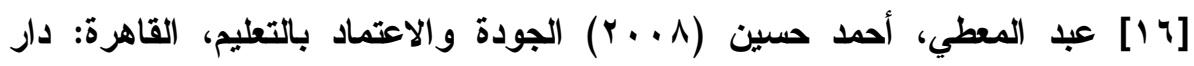
السحاب.

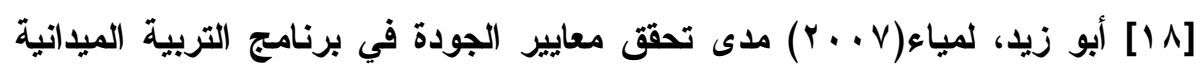

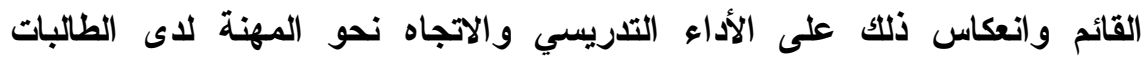

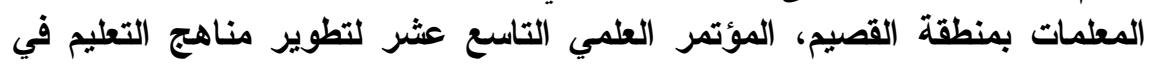
ضوء معايير الجودة، جامعة عين شمس، المبم، المجلد الرابع. 
مجلة كلية التربية، جامعة الأزهر، العدد: (9 17 الجزء الثاني) يوليو لسنة 17 ـابم

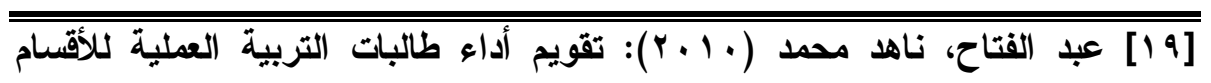

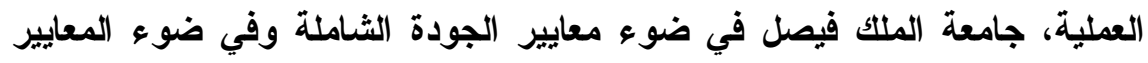

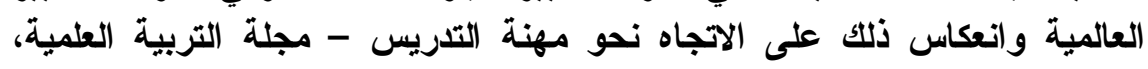
المجلا س ا ا-يوليو. وانكان.

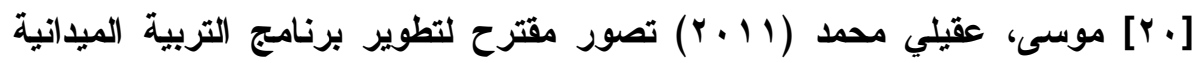

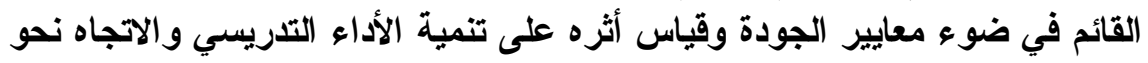

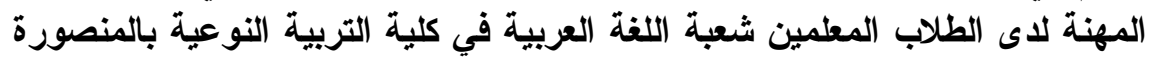

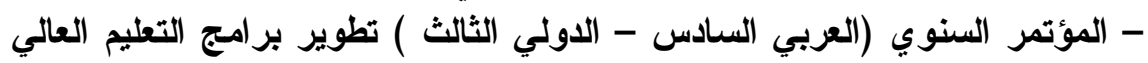

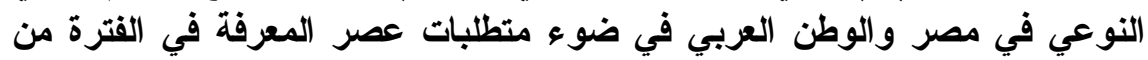

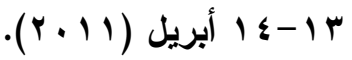

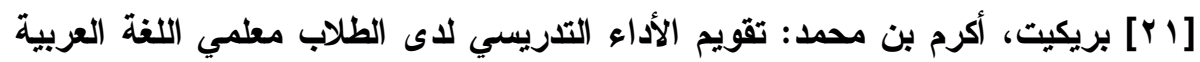

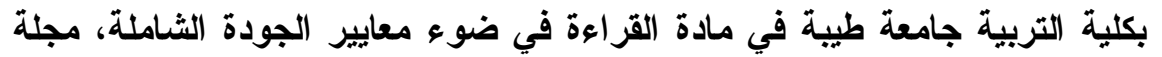

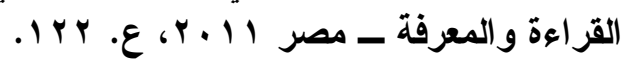

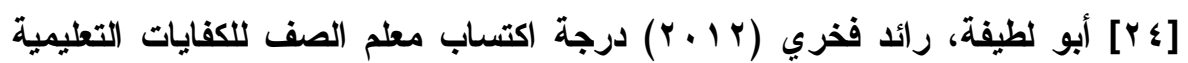

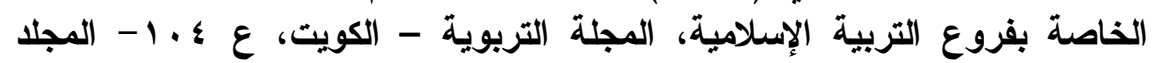
צ ب - الجزء الثاني سبتمبر.

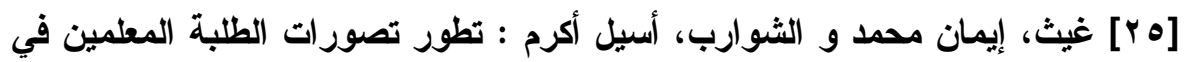

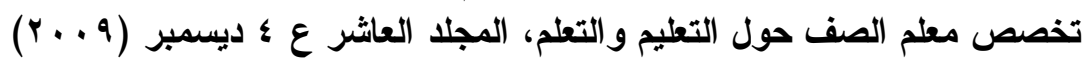

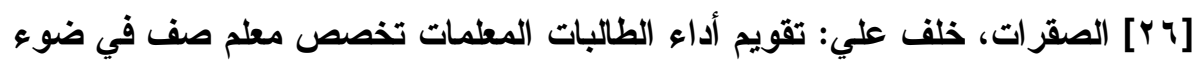

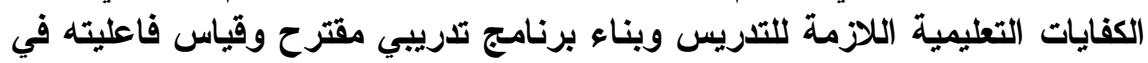
جامعة مؤتة - الأردن، مجلة اتحاد الجامعات العربية للتربية ولئية وعلم النفس المجلئ

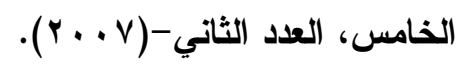

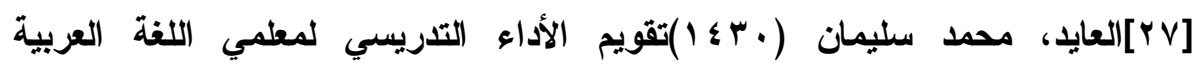

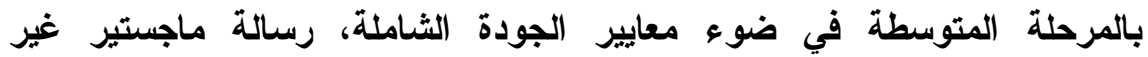
منثورة، جامعة الملك سعود.

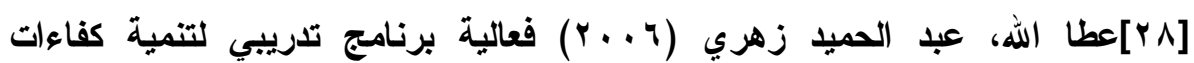

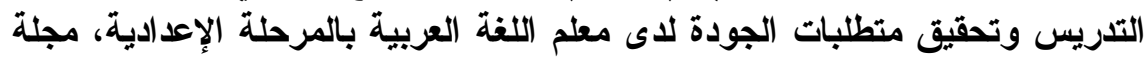

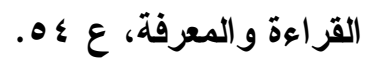


مجلة كلية التربية، جامعة الأزهر ، العدد: (199 الجزء الثاني) يوليو لسنة 19 بامب

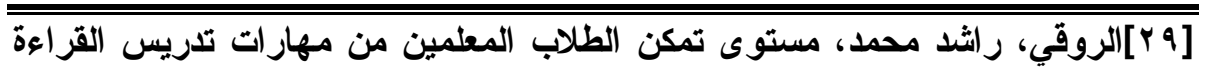

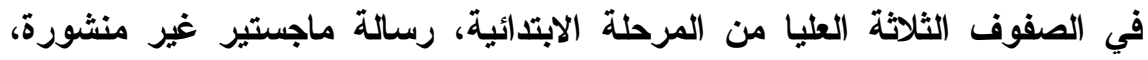

جامعة أم القرى.

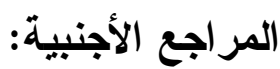

[30] Harrys. Hertz (2001) Baldrigenational Quality program national.

www. @uality. Nist- govl nstitate of andte chnology, web site.

[31]Cole, P. and chan, L (1994)Teaching Princi plesand practice edition. New york: prentice hall.

[32]Culling ford, c.(1995)The effectine teacher.

London: cassell Education. 